\section{EL PROFESIONAL EN CIENCIAS ECONÓMICAS \\ Y LA RESOLUCIÓN DE CONFLICTOS}

\author{
THE PROFESSIONAL IN ECONOMIC SCIENCES \\ AND CONFLICT RESOLUTION
}

\section{Gastón Maximiliano Cabral}

\section{RESUMEN}

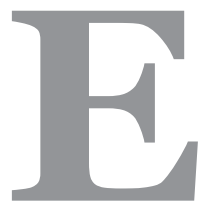

ste artículo explica los métodos de resolución de conflictos alternativos del sistema judicial. A su vez, hace un resumen de cada uno de ellos y explica los requisitos que debe cumplir el profesional en ciencias económicas para ejercer como mediador en la provincia de Chaco.

Palabras clave: mediación, conciliación, arbitraje, conflictos, mediador.

\begin{abstract}
This article explains the alternative dispute resolution methods of the judicial system. In the other hand, summarizes each one of them and explains the requirements that the professional in economic sciences must fulfill to practice as a mediator in the province of Chaco.
\end{abstract}

Keywords: mediation, conciliation, arbitration, conflicts, mediator.
Gastón Maximiliano Cabral gaston.cabral@gmail.com

Facultad de Ciencias Económicas

Universidad Nacional del Nordeste

ARGENTINA 


\section{LOS MÉTODOS ALTERNATIVOS DE RESOLUCIÓN DE CONFLICTOS -M.A.R.C.-}

En el nuevo Código Procesal Civil y Comercial de Chaco (CPCCCH), en el Art. 50 inc.2 establece que, aun sin requerimiento de parte, los jueces y tribunales deberán...intentar una conciliación total o parcial del conflicto...pudiendo proponer o promover que las partes deriven el litigio a otros medios alternativos de resolución de conflicto -MARC- (...).

Los métodos alternativos de resolución de conflictos (MARC) son procedimientos para resolver conflictos alternativos al sistema judicial. Estos métodos están compuestos principalmente por la Mediación, Conciliación y Arbitraje, entre otros.

La Mediación es un procedimiento no adversarial en el que un tercero neutral, facilita que las partes arriben consensuadamente a la solución de su conflicto. Esto significa, que el mediador es un tercero ajeno al asunto que no toma una decisión para resolver el caso, sino que ayuda a las partes a que ellas mismas encuentren una solución, mediante el uso de técnicas para mejorar la comunicación entre ellas.

El procedimiento de la mediación se rige por los principios de: voluntariedad, confidencialidad y neutralidad, entre otros.

La Conciliación es un procedimiento similar a la mediación, con la diferencia que el tercero neutral, que oficia de conciliador, sugiere soluciones a las partes.

En el Arbitraje, la participación del tercero aumenta hasta el grado de decidir la resolución del conflicto, similar a la intervención de un Juez.

Por otro lado, el Art. 310 de dicho Código define a la Transacción como una forma de finalización del juicio, pero no precisa a que M.A.R.C. hace referencia. En consecuencia, podemos entender a la Transacción como un acuerdo de partes fruto de la mediación, conciliación, arbitraje o algún otro método.

Como se puede apreciar, la mediación es importante porque sus procedimientos son la base sobre la cual parten los demás métodos.

\section{VENTAJAS DE LOS M.A.R.C.:}

- Descomprimen el Sistema de Justicia.

- Disminuyen los costos y el tiempo para resolver conflictos.

- Los acuerdos, al ser voluntarios, tienen mayor perspectiva de cumplimiento.

- En los juicios iniciados, suspende los plazos (Art. $313 \mathrm{CPCCCh}$ ).

- Los profesionales en Ciencias Económicas tienen incumbencia. 


\section{LA MEDIACIÓN Y EL PROFESIONAL EN CIENCIAS ECONÓMICAS}

En este apartado, desarrollaremos uno de los M.A.R.C: la Mediación.

A diferencia de otras provincias, según nuestra Ley Prov. $\mathrm{N}^{0} 1601-\mathrm{M}$, los profesionales en ciencias económicas (contadores y licenciados) pueden ser mediadores en cuestiones prejudiciales o extrajudiciales, no así, en los procesos en trámites, en los cuales solo pueden participar como comediadores, formando un equipo junto a otro comediador con título de abogado.

Para ejercer la mediación, hay que inscribirse en el Registro de Mediadores de la provincia a cargo del Superior Tribunal de Justicia, para lo cual se exige rendir un examen.

El art. 6 de la Ley Provincial de Mediación, establece los siguientes requisitos para registrarse: a) poseer título universitario de grado de cualquier disciplina, b) haber completado la capacitación básica en mediación aprobada por el Ministerio de Justicia y DDHH de la Nación, c) tener domicilio en la provincia, y d) disponer de oficinas para realizar reuniones de mediación.

El profesional matriculado como mediador puede firmar acuerdos otorgándoles el carácter de titulo ejecutivo. Además, dichos acuerdos, en determinadas situaciones, requieren ser homologados. En caso de incumplimiento, las partes pueden interponer acciones judiciales.

El siguiente cuadro resume el carácter de los acuerdos según su homologación y acción legal en caso de incumplimiento.

\begin{tabular}{|l|l|l|}
\hline \multirow{2}{*}{$\begin{array}{l}\text { Incumplimiento de acuerdos } \\
\text { firmados ante mediador matriculado }\end{array}$} & No Homologados & Ejecución de titulo ejecutivo \\
\cline { 2 - 3 } & Homologados judicialmente & Ejecución de sentencia \\
\hline
\end{tabular}

Para finalizar, es dable resaltar que el profesional en ciencias económicas debe manejar las distintas herramientas para abordar conflictos para complementar su actuación en cada ámbito en el que se desenvuelva. (ej.: empresariales, de organizaciones sociales, administración pública, instituciones educativas, etc.).

\section{REFERENCIAS BIBLIOGRÁFICAS}

Caram, Eilbaum, \& Risolia (2013) Mediación: Diseño de una práctica. Buenos Aires. Astrea.

Ley Provincial de Mediación No 1601-M (antes Ley 6051).

Ley Provincial de Mediación Familiar No 1782-C (antes Ley 6.448). 
Ley Provincial de Mediación Penal No 1181-N (antes Ley 4.989).

Nuevo Código Procesal Civil y Comercial de la Provincia de Chaco - Ley 7.050.

Suarez, M. I. (1996) Mediación: Conducción de disputas, comunicación y técnicas. Buenos Aires. Paidos.

\section{COMO CITAR ESTA COMUNICACIÓN}

CABRAL, Gastón Maximiliano. El profesional en ciencias económicas y la resolución de conflictos. Revista de la Facultad de Ciencias Económicas - UNNE, Argentina. Volumen 22, Núm. 1, enerojunio 2019, ISSN: 1668 - 6365. Págs. 115 - 118. DOI: http://dx.doi.org/10.30972/rfce.2213952

\section{CURRICULUM VITAE}

\section{Gastón Maximiliano Cabral}

Contador Público - UNNE. Mediador Matriculado, Superior Tribunal de Justicia. Cursando $2^{\circ}$ año de la carrera de abogacía - UNCAUS.

Investigador y expositor de trabajos de investigación en Jornadas de la Federación Argentina de Consejos Profesionales de Ciencias Económicas - F.A.C.P.C.E.-, Argentina. gaston.cabral@gmail.com 